
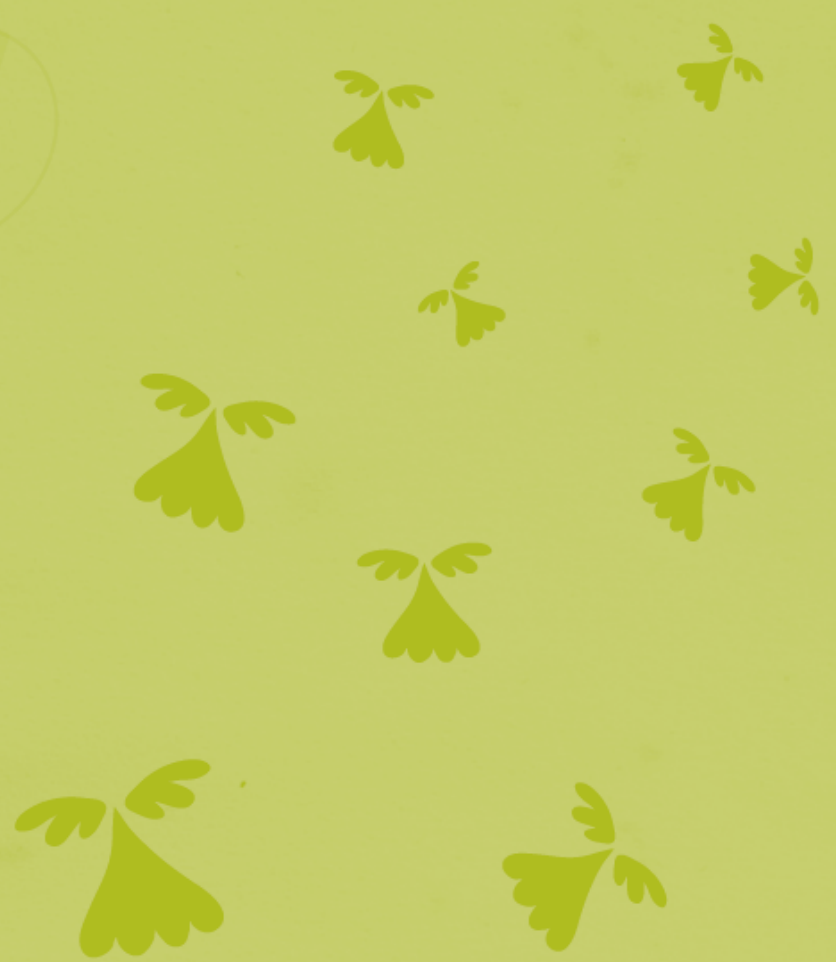

8
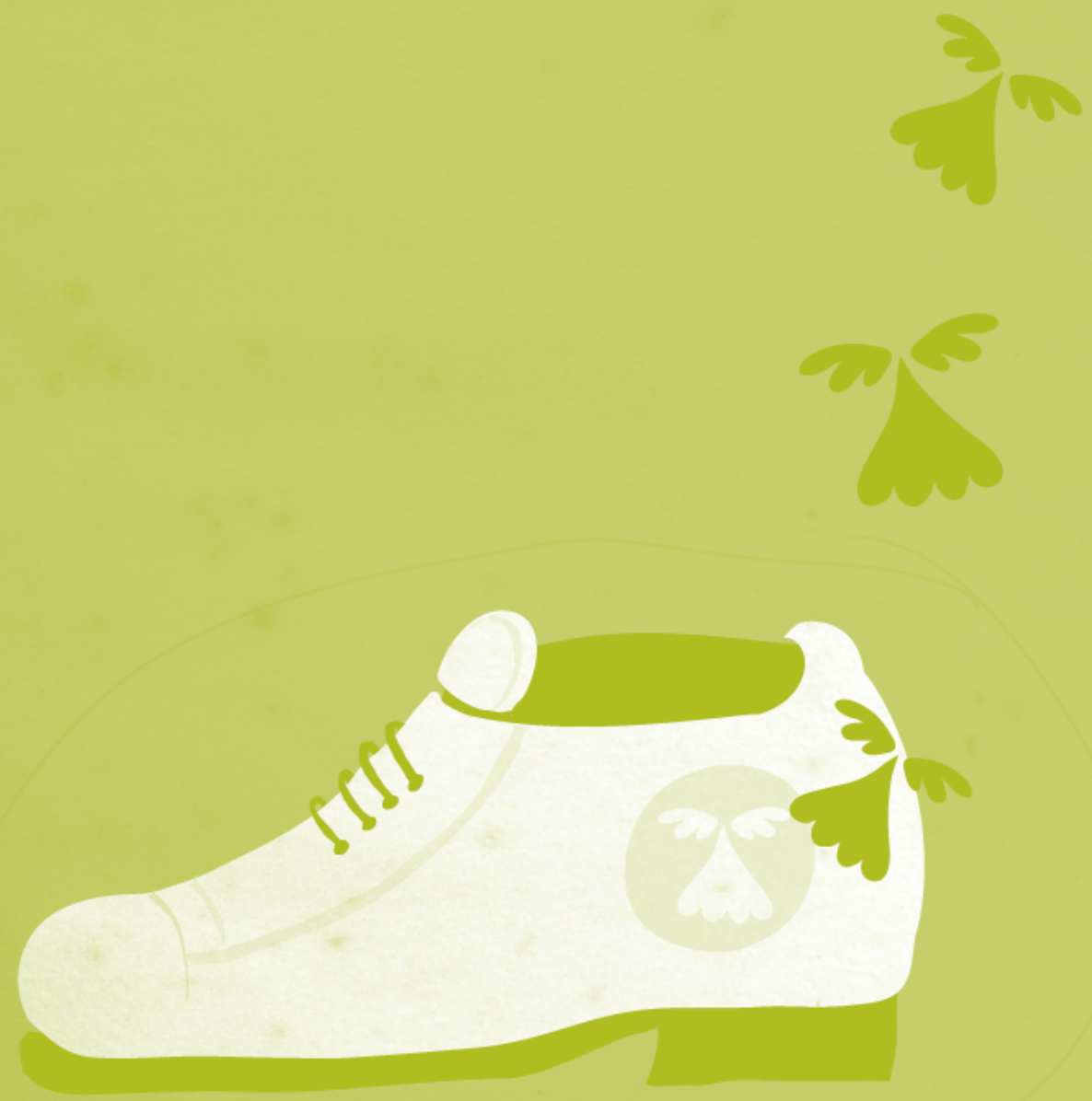


\section{Olhando a marca pela sua enunciação: aproximações para uma teoria da marca contemporânea}

Evandro Renato Perotto

- Mestre em Ciências da Comunicação pela Universidade de Brasília (UnB)

- Graduado em Comunicação Social pelo Centro Universitário de Brasília

- Pesquisador do Núcleo de Design para Questões Socioambientais da UnB

- Professor do Curso de Desenho Industrial da UnB

- Consultor nas áreas de desenvolvimento de marca e de sistemas de identidade visual

- perotto@unb.br 


\section{Resumo}

Esta pesquisa identificou quatro aspectos importantes que caracterizam a marca contemporânea como um fenômeno essencialmente discursivo, cujo sentido decorre de sua enunciação intertextual e estruturação discursiva única. Diante de lacunas teóricas que a expliquem, esta pesquisa desenvolveu uma aproximação teórica baseada em pressupostos da produção de sentido.

PALAVRAS-CHAVE: COMUNICAÇÃO • ENUNCIAÇÃO. PRODUÇÃO DE SENTIDO • MARCA. CONCEITO DE MARCA • IDENTIDADE DE MARCA

\section{Abstract}

This survey identified four important aspects that characterize the contemporary brand as basically a phenomenon of discourse, the meaning of which stems from its inter-textual enunciation and the unique structuring of the discourse. On account of the theoretical gaps by which it is explained, this survey has developed a theoretical approach based on assumptions for creation of meaning.

KEYWORDS: COMMUNICATIONS • ENUNCIATION • CREATION OF MEANING • BRAND. BRAND CONCEPT • BRAND IDENTITY

\section{Resumen}

Esta investigación identificó cuatro aspectos importantes que caracterizan la marca contemporánea como un fenómeno discursivo en su esencia, cuyo sentido resulta de su enunciación ínter textual y de su estructuración discursiva de cualidades únicas. Frente a los vacíos teóricos que la expliquen, esta investigación desarrolló una aproximación teórica basada en los presupuestos de la producción de sentido.

PALABRAS CLAVE: COMUNICACIÓN • ENUNCIACIÓN • PRODUCCIÓN DE SENTIDO • MARCA • CONCEPTO DE MARCA • IDENTIDAD DE MARCA 
A pesar de toda a sua onipresença e intensidade, a marca contemporânea ainda é algo polissêmico e de contornos um tanto indefinidos. Desde fins da década de 80 do século passado, a marca assumiu uma posição de centralidade nas ações e comunicações de organizações de todo tipo. Mais do que um nome e suas representações, a marca contemporânea é um fenômeno que implica uma grande carga simbólica e ideológica, pois sua presença evoca e mobiliza sistemas de valores sociais e culturais.

A marca, que inicialmente se instituiu no âmbito das trocas comerciais, tornou-se o ponto de articulação de diversos processos sociais, especialmente econômicos, comunicacionais e de consumo, como uma característica proeminente das sociedades industriais e pós-industriais. Em um contexto de aceleração dos processos sociais e de produção, de hiperoferta, de intensificação e saturação dos fluxos de distribuição, comunicação e semióticos (COSTA, 2006, p. 57-60), favorecidos e sustentados pelo desenvolvimento de meios técnicos e pelo crescimento dos setores secundário e terciário, a marca se tornou complexa e multidimensional. E, paradoxalmente, o faz com uma intrigante "naturalidade". E, de expressões primárias em torno de um signo, a sua estruturação modificou-se em complexos sistemas semióticos, respondendo às demandas das práticas sociais. Da mera identificação, pela aposição de um signo a um produto ou lugar, a marca ampliou e aprofundou de modo considerável as funções que desempenha, se inserindo e acelerando aqueles processos de que participa.

\section{Duas dificuldades para a conceituação da marca}

A gestão de marca não é uma atividade exclusivamente ligada ao mercado, à produção ou ao consumo, mas vem sendo amplamente utilizada também por diferentes instituições públicas, por organizações não-governamentais ambientalistas, sociais e culturais, por movimentos e correntes de idéias, por personalidades dos meios políticos e culturais etc. Por isso, não nos causa nenhuma estranheza, por exemplo, o escritor Paulo Coelho declarar que "sou uma marca, me reconheço como uma marca" 1 ou uma prefeitura municipal gerenciar a sua imagem e reputação junto aos cidadãos como se estivesse oferecendo algum tipo de produto ao mercado. Este fato da marca permear processos tão diversos nos aponta duas questões. 
A primeira é que, se a marca ocorre em processos interativos tão distintos e com atores e objetivos diversos daqueles das marcas comerciais, então ela não é um fenômeno de ordem econômica, ainda que seja essencial para os ostensivos processos de mercado. A marca, então, é algo que deveria ser descrito para além dos processos que atravessa e participa e, desta forma, não poderia ser apreendida ou explicada com base em seus usos e funcionalidades restritas a determinadas situações, sob o risco de transferência ou generalização de especificidades. Ou, ainda, de cair na falácia simplista de caracterizar por pressupostos de mercado os outros processos que incluem a marca entre as suas práticas sociais, como se a lógica da marca fosse a mesma que a de mercado. O Museu do Louvre, o Greenpeace e o Fórum Econômico Mundial, por exemplo, têm objetos e discursos diferentes dos da The Body Shop, Vale ou Nike, porém possuem e gerenciam suas marcas de modo semelhante, sem que isso implique podermos descrever e explicar o fenômeno da marca naquelas pelos pressupostos de suas funções em circuitos econômicos. A marca contemporânea, então, estaria camuflada no universo profuso de suas aplicações e visibilidade social. Atribuímos a isso uma das dificuldades de sua descrição e compreensão.

O segundo aspecto, que decorre do anterior, é a dispersão e a fragmentação de conhecimentos capazes de explicar ou mesmo descrever a marca para além de tais particularizações. Quase todos os textos que encontramos não nos pareceram adequados ou suficientes para dar conta da amplitude do fenômeno da marca. As inúmeras variações de abordagens e enfoques se distribuem entre os campos da Comunicação, do Marketing e do Design, cada uma com um ponto de vista particular. Não são visões necessariamente contraditórias, mas parciais e complementares e, na maior parte dos casos, comprometidas com os funcionalismos e utilitarismos que visam à operacionalização e aos resultados da marca, e não propriamente descrever o fenômeno. Assim, uma explicação de caráter fundamental e teórico da marca não poderia ser obtida pelo mero agrupamento e articulação desses conhecimentos isolados. Contudo, não podemos depreciar tais saberes, mesmo porque muito do que é conhecido e construído sobre a prática social da marca se funda naquelas abordagens, que apreendem parte do fenômeno e que seguramente respondem a muitas das questões demandadas no âmbito em que foram propostas.

\section{Caracterização do fenômeno da marca: nosso ponto de partida}

Mas se a marca é um fenômeno que atravessa distintos processos, certamente as suas explicações devem se situar na transcendência destes. Foi preciso inicialmente identificar o que caracteriza a essência do fenômeno para, então, poder desenvolver uma descrição e teorização fundamental que nos permita apreender e compreender a marca e seus processos. Diante da lacuna apontada, nosso trabalho buscou uma aproximação teórica que, ainda que não nos permitisse avançar muito, pois o caminho é longo, pelo menos nos apontasse uma possibilidade plausível para a construção de uma 
teoria da marca. Impusemo-nos, então, uma pergunta inicial: quais seriam as características essenciais do fenômeno da marca, aquelas que são observadas em todas as situações de sua ocorrência?

\section{As quatro características essenciais da marca contemporânea}

Entendemos que a marca é uma instituição social ${ }^{2}$, isto é, uma construção simbólica compartilhada, uma abstração, resultante de processos e estratégias de objetivação e significação. Portanto, a marca é um fenômeno que tem uma factibilidade histórica e objetiva. Ser uma instituição nos permitiria caracterizar alguns aspectos do processo da marca contemporânea, mas ainda não descreveria a sua natureza.

Identificamos que a marca contemporânea é um fenômeno de natureza essencialmente discursiva. Independentemente da situação, formas ou condições em que circula, a marca é um projeto discursivo. Não se trata de um tipo de discurso comum, mas que se organiza sob uma determinada lógica e estruturação que tornam a marca um gênero discursivo de características únicas, capaz de assimilar uma impressionante variação de conteúdos e de ser aplicado a universos bastante distintos.

Toda construção de marca, invariavelmente, é um processo que procura produzir algum sentido e ser significante, atuando na dimensão simbólica da sociedade, interagindo com os valores e sistemas ideológicos dos indivíduos ${ }^{3}$ e categorias sociais. Seu sentido é resultante das estratégias discursivas que a marca realiza, especialmente no espaço mediático ${ }^{4}$, e das interações simbólicas que promove frente a todo um conjunto de sistemas de valores e vetores sociais presentes na semiosfera ${ }^{5}$. Comentando sobre a importância do sentido para a marca, Semprini (2006, p. 20) considera que o primeiro objetivo da marca contemporânea, a qual prefere chamar de pós-moderna, é a proposição de um "projeto de sentido".

Mas a marca se caracteriza, ainda, por outra coisa fundamental: discursivamente ela se institui como um sujeito pela construção social de sua identidade. De acordo com Verón (2005, p. 217), é da natureza de todo discurso construir uma "imagem de quem fala", mas, no caso específico da marca contemporânea, essa qualidade discursiva é preponderante. Chaves (2003, p. 12) chama isso de "protagonismo do sujeito", que resulta

20 termo é usado aqui no sentido descrito por Berger e Luckmann (2004).

3 Considerados em sentido sociológico e não como uma individuação psicológica.

4 Adotamos os termos "meios", "mediático" e suas variações, por entendermos que aquelas preservam melhor a etimologia latina das palavras que têm como origem "medium" (meio) e "media" (meios).

5 Conceito desenvolvido por Yuri Lotman. Consiste na tese de que qualquer sistema de comunicação ou ato comunicativo deve estar imerso num espaço semiótico e que fora desse espaço não poderia haver nem comunicação, nem linguagem, ou mesmo o sentido. 
em um processo de subjetivação das mensagens, ou seja, os discursos da marca tendem muito a evidenciar quem está comunicando, em detrimento do que está sendo comunicado.

Pelas características comentadas acima, entendemos que o fenômeno da marca poderia resumidamente ser descrito como: (1) é uma instituição social; (2) é um fenômeno discursivo; (3) procura produzir algum sentido e ser significativa; e (4) constrói uma identidade. Percebemos que essas características são inerentes ao fenômeno da marca contemporânea e independem da natureza e tipo do sujeito enunciador (produto, serviço, movimento, organização, pessoa etc.), ou do contexto de enunciação (econômico, político, cultural etc.).

\section{A marca como um fenômeno discursivo e a análise de sua enunciação}

Isolar esses elementos foi apenas o primeiro passo. Sobre eles ainda teríamos que buscar uma angulação de abordagem e construir uma análise que desse conta do fenômeno e que pudesse nos levar à sua teorização. Queríamos desenvolver algum conhecimento fundamental sobre a marca, uma explicação mais ampla do fenômeno, o que nos apontava um sentido contrário àqueles interessados na aplicação técnica.

$\mathrm{Na}$ literatura especializada, poucos autores consideram a marca como discursiva, e mais raros ainda aqueles que avançaram em análises teóricas construídas com base em sua discursividade. Nesta última linha, Semprini (2006), Costa (2006) e Kapferer (2003) desenvolveram consistentes trabalhos sobre a marca e, embora com tonalidades diferentes, nos apontando que era pertinente e plausível uma abordagem teórica do fenômeno da marca analisando-a por sua natureza discursiva.

Como um discurso, a marca implica questões de seu enunciado, o objeto textual que resulta de processos de produção, e questões de sua enunciação, o conjunto dos vetores que intervêm na produção de seus discursos. No caso da marca, a enunciação é extremamente relevante pela sua situação de articulação de diversos vetores sociais, tanto no âmbito da produção quanto da circulação e recepção. Nossas pesquisas nos deram convincentes razões para crer que o sentido de uma marca não está imanente

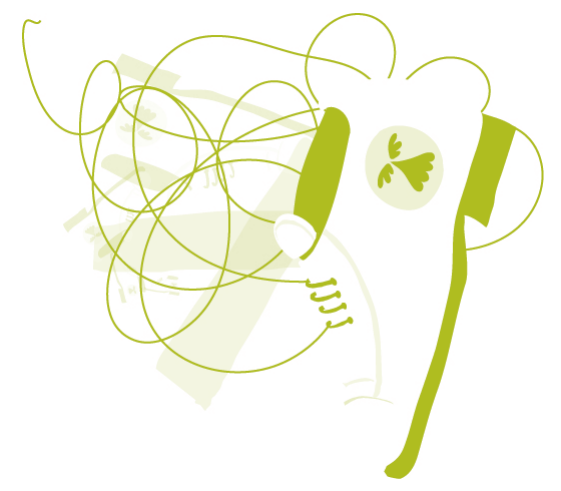


na textualidade do seu discurso, mas nas mediações e na força de mobilização semiótica extratextual e intertextual que estabelece por sua enunciação. Encontramos em Fausto Neto (1999, p. 9) indicações de que "o sentido não se doa, mas é construído pelo trabalho das enunciações discursivas”. Assim, vislumbramos que as descrições e explicações para o fenômeno da marca contemporânea poderiam ser baseadas, então, em análises e discussões sobre sua enunciação. Mas como abordar a enunciação da marca?

\section{Os aportes teórico-metodológicos da produção de sentido}

Encontramos na perspectiva da produção de sentido, desenvolvida por Verón (1980 e 2005), um suporte teórico e metodológico para sustentar a análise da marca pela sua enunciação, e que ainda mostrava potencial metodológico para dar conta daquelas suas quatro características essenciais. Tal abordagem considera "o processo que vai da produção de sentido até a 'consumação' de sentido, sendo a mensagem o ponto de passagem que sustenta a circulação social das significações”. (VERÓN, 2005, p. 216)

Em Verón (1980, p. 59-60), a questão do sentido não é imanente ao discurso, mas implica e se explica sempre por algo que está para além dos aspectos intrínsecos a ele. Sendo o sentido discursivo estabelecido sobretudo pela enunciação, é na sua análise que estaria a chave para a compreensão da significação. Diferente de outras, a produção de sentido não exclui da análise os aspectos da dimensão pragmática. Ao contrário, considera-os como participantes efetivos do processo de significação na medida em que deixam traços no discurso.

Tal aporte teórico-metodológico da produção de sentido se mostrou adequado e promissor, já que não considera o discurso (o enunciado) como objeto de análise - embora o reconheça como importante -, mas busca identificar e mapear aquilo que determina e caracteriza tal discurso (a enunciação). Pela característica mediadora da marca, tal análise mostrou-se especialmente adequada.

\section{A marca conceituada pela enunciação: a proposta de um outro olhar}

Enredada por vetores de esferas diferentes, a marca atua como um ponto de passagem e articulação dos diversos processos de que participa, cumprindo funções variadas. É um fenômeno multidimensional, capaz de realizar a mediação e síntese desse complexo em que está inserida, articulando processos que dialogam com e por meio dela discursivamente. Pela marca contemporânea transitam fluxos e processos de produção e reconhecimento de valores e significados sociais, estabelecendo seu sentido discursivo pela sua enunciação, particularmente no âmbito das relações intertextuais, e poderia ter explicações pela análise de seu modo de produção. 
De acordo com os pressupostos da produção de sentido, o modo de produção de um discurso tem, por um lado, o processo de produção, que, pautado por regras e coerções discursivas (a gramática de produção), realiza as operações de investimento de sentido nas matérias significantes, e, por outro, as condições de produção, que definem a posição social do sujeito enunciador. Esses dois aspectos, que Verón chama de momentos, são separados apenas em termos teóricos. Na prática, eles ocorrem simultaneamente. Vamos comentar melhor como se articulam no discurso essas duas dimensões na enunciação da marca.

\section{0 investimento de sentido: intertextualidade e historicidade na marca}

Pela perspectiva da produção de sentido, não há sentido que não seja discursivo. Mas o discurso "não é jamais um lugar de sentido" (VERÓN, 1980, p. 205). Isso implica que o sentido discursivo da marca está, portanto, nas relações que estabelece com o domínio do extradiscursivo, do intertextual e do contextual, e não pode ser explicado nela, que é apenas um ponto de passagem e articulação entre gramáticas ou códigos ${ }^{6}$ de operações discursivas de produção e reconhecimento de sentido. A apreensão e análise da gramática de produção e das gramáticas de reconhecimento é que permite compreender a intertextualidade do sentido da marca.

Verón chamou de investimentos de sentido a essas operações de conformação discursiva, o "que não é senão a colocação do sentido no espaço-tempo, sob a forma de processos discursivos" (1980, p. 191). É por meio dessas regras de investimento de sentido que se articulam e se fazem circular os valores dos sistemas ideológicos ${ }^{7}$ em que ela, a marca, se insere. Esses sistemas ideológicos compreendem as grandes estruturas de valores e discursos - as macronarrativas - que organizam a vida econômica, social, política, cultural etc., mas também as idiossincrasias, expectativas, desejos, projeções etc. de indivíduos e grupos - as micronarrativas -, além daquelas próprias a cada marca. Essa composição pode variar a cada situação de enunciação. Assim, a marca faz circular tais valores por sua enunciação, mas também se faz circular socialmente por eles.

O caráter de intertextualidade que permeia os discursos sociais e que foi observado por Verón: a "impureza significante e códica" (1980, p. 78), que contribui para o sentido dos discursos, que dialogam entre si e interagem, se co-determinando. Esse aspecto nos parece muito importante para compreensão da grande capacidade de mediação e mobilização simbólica da marca contemporânea. O universo em que uma

6 Verón considera código o conjunto das regras e coerções que determinam as operações de investimento de sentido.

7 Neste trabalho usamos sempre o termo "ideologia" em sentido amplo, como sistema simbólico que incorpora os valores sociais e culturais, as representações etc., e não restritivamente a aspectos políticos. 
determinada marca circula contribui, pela interdiscursividade da semiose social, para produzir o reconhecimento - e efeito - de seu sentido.

No nosso caso, percebemos que o discurso da marca, por sua situação peculiar de enunciação, concretiza o princípio de intertextualidade nas três dimensões apontadas por Verón (1980, p. 79-80). Observamos que: (1) a marca estabelece diálogos com as demais marcas de seu gênero, o que nos permitiria compreender, por exemplo, o sentido da marca de um banco comercial em relação às marcas de outros bancos similares; (2) a marca dialoga com outros universos discursivos, interagindo com outras expressões e formas narrativas e, por exemplo, o sentido e significado das marcas Adidas e Puma para o movimento hip-hop somente pode ser compreendido em função dos diálogos entre seus discursos há quase 40 anos; e (3) a marca dialoga com outros discursos que "embora participem de etapas ou momentos do processo de sua produção, não aparecem na 'superfície' do discurso 'produzido' ou 'terminado'”' (VERÓN, 1980 , p. 80). Este último aspecto da intertextualidade é muito acentuado nos discursos da marca, particularmente porque eles circulam vínculos de imagem muito fortes relacionados aos valores psicossociais e sistemas de valores da recepção. Isso pode ser bem observado nas sutis sugestões do sentido de inclusão ou exclusão social nos discursos de determinadas marcas.

A enunciação da marca é sempre um fenômeno histórico que resulta e reflete as condições de intertextualidade de sua produção. Por isso torna-se difícil a marca contemporânea ser compreendida fora de suas relações significativas ou da especificação da situação de enunciação: não há qualquer possibilidade de sentido de uma marca fora da intertextualidade e da intersubjetividade. Esse ponto nos leva de volta àquela questão da mudança de postura já comentada: quanto mais a marca é reconhecida e se estabelece como uma instituição social, menos os seus operadores serão "proprietários" dela e, freqüentemente, a arrogância na sua gestão resulta desastrosa ${ }^{8}$.

A análise dos processos de produção - as gramáticas e operações de investimento de sentido - nas marcas contemporâneas nos levou a descrever que as principais características de estruturação do seu discurso são: (1) centralizante, pois quaisquer manifestações da marca são estrategicamente coordenadas por um consistente projeto de sentido, (2) totalizante-convergente, pois todas as comunicações e ações devem participar da construção da marca e expressar seu projeto de sentido, que se faz manifestar na arquitetura das lojas e fábricas, nas cores e mobiliário dos ambientes, no projeto dos produtos que assina, na publicidade, no atendimento por seus agentes, pelos tipos de ações de responsabilidade social e ambiental em que se envolve, pelos patrocínios que faz, pelos eventos não-comerciais que realiza..., e (3) multidimensional, pois suas gramáticas de produção se expandiram para conseguir traduzir/adaptar e controlar a diversidade de operações de investimento de sentido em meios, técnicas

8 Vide o meteórico caso da Petrobrax, por exemplo. 
e linguagens cada vez mais específicos e experienciais. Definitivamente, a marca contemporânea fala mais, fala diferente, fala de outras coisas, fala em todas as oportunidades e fala em vários dialetos. "O corpo institucional se hipersemantiza" (CHAVES, 2003, p. 14).

\section{As condições de produção da marca: definindo a marca como enunciadora}

Quando Verón se referia ao fato de os discursos serem situados, ele não os restringiu apenas à situação frente à semiose, mas também apontava para uma característica elementar, já comentada, de que o discurso "é sempre uma mensagem situada, produzida por alguém e endereçada a alguém” (VERÓN, 1980, p.77). Seu sentido está condicionado, além da situação produzida por aquelas operações de investimento comentadas acima, à percepção de diferenças de localização dos sujeitos envolvidos. A existência desse sujeito produtor implica necessariamente um conjunto de vetores que o localizam socialmente, que lhe determinam a situação de enunciador considerado "em termos de sua posição social” (VERÓN, 1980, p.81).

O sujeito-enunciador deve ser localizado e situado em relação à sua intertextualidade por meio de índices discursivos ${ }^{9}$. A marca, portanto, é um sujeito que explícita ou implicitamente relaciona o que diz com quem é: não somente fala algo, mas fala algo a partir de algum lugar social. Essa é a razão pela qual a marca, pela perspectiva da produção de sentido, é um enunciador social e histórico. Vamos avançar na discussão sobre enunciador com base nesta eloqüente citação de Verón:

"É essencial compreender que, quando nos propomos a considerar a sociedade como uma semiose, esta nos aparece como uma rede de desvios intersignificantes, como um tecido multidimensional de distâncias interdiscursivas. (...) trata-se de assinalar diferenças de 'potencial' significante entre as posições no interior da rede: são essas diferenças que exprimem, no nivel do sentido, a dinâmica do funcionamento social, os avatares do poder, a distância entre as leituras do 'real'." (1980, p. 207)

Consideramos esse aspecto central para o entendimento da marca e da peculiaridade de seu discurso. Quando falamos de estabelecer um lugar no espaço social, não estamos falando de outra coisa senão da construção ideológica de uma posição no imaginário social. Onde o enunciador é percebido produz sentido discursivo, pois é uma posição significante porque define proximidades e distâncias simbólicas na intertextualidade. De modo bastante natural, os indivíduos costumam organizar sua rede pessoal de relacionamentos por proximidades e afinidades de atributos e perso-

9 Verón (1980 e 2005) e Fausto Neto (1999) utilizam as expressões "marcas" ou "marcadores" para designar os índices que permitem localizar o enunciador. Neste texto, optamos por usar "índices discursivos" para evitar qualquer ambigüidade com o termo "marca". 
nalidade. Acreditamos que de modo análogo realizam operações de mapeamento de marcas, o que poderia explicar a ênfase dos elementos ou componentes psicossociais na marca ${ }^{10}$.

No caso das marcas, postulamos que esse espaço imaginado se constitui em uma das camadas da semiose e se configura por uma rede ou mapa de posições percebidas em termos de reconhecimento no universo das marcas. Mas essa posição somente pode ser definida em termos de sua identidade, como enunciador. A própria rede de posições percebidas oferece simultaneamente os referenciais de semelhança e diferença que permitem perceber a marca pela identidade e localizá-la significativamente como enunciadora. A esse mapa simbólico do universo das marcas chamamos de atualidade identitária, e em termos dessa atualidade é que podemos compreender e explicar a centralidade da identidade, do posicionamento e da imagem da marca contemporânea no contexto hipersaturado de marcas e a acentuação de sua imprescindível função dicotômica de identificação-diferenciação.

O discurso da marca na atualidade identitária é uma afirmação simultânea do ser e do não-ser, da semelhança e da diferença, da identidade e da alteridade. A atualidade identitária se constitui, portanto, na dimensão da intertextualidade e da intersubjetividade da marca. As condições de produção discursivamente constroem um enunciador, que é um sujeito que ocupa um lugar de ser ${ }^{11}$, que é o reconhecimento de sua identidade uma localização significada, significante e historicamente determinada por seus índices discursivos pelas distâncias interdiscursivas percebidas e demarcadas pelos discursos de um grupo de marcas em relação à rede da semiose. O sentido, portanto, pode ser entendido em termos de diferenças não somente pelo modo como algo é dito, mas principalmente a partir de que lugar na atualidade identitária. Por isso, a análise semiótica da marca deve ser sempre relacional.

Esse aspecto levanta alguns pontos que poderiam ser incluídos na análise da marca: as manobras discursivas de acentuação das diferenças, ou proximidades, de lugar na semiose de uma marca em relação às similares ou às concorrentes, a manipulação deliberada dos indicadores discursivos para proposições de posicionamento social, a ênfase das distâncias interdiscursivas significantes (manipulando frustrações, projeções e desejos, por exemplo). Entendemos que a análise de tal "diferença de potencial" entre as marcas pode ser uma importantíssima ferramenta para compreensão dos processos discursivos de construção da identidade como um indexador semiótico, ou para descrição da imprescindível função dicotômica de identificação-diferenciação da marca

10 Sobre isto, ver Aaker (1998), Ellwood (2004), Kapferer (2003), Kotler (2000), Randazzo (1996).

110 "lugar de ser" é um conceito que desenvolvemos e que supõe a posição significante de identidade do sujeito na semiose social. A identidade de um sujeito social, porquanto discursiva, é determinada por seus vetores de sentido na rede de significação da semiose, o que difere de "posição social", definida por vetores de localização dentro de uma dada estrutura social. 
contemporânea. Poderíamos ainda especular sobre a possibilidade de avaliar até que ponto a questão do posicionamento de marca, definido em termos da identidade e posição na semiose, influi na produção do sentido e imagem de marca.

Pode parecer um detalhe, mas considerar sua identidade por essa perspectiva implica uma importante mudança de postura na gestão da marca: a identidade pode ser proposta, mas jamais pode ser controlada, pois é sempre o resultado de uma construção dialógica, de uma negociação de sentido. Portanto, a identidade não é uma característica imanente aos enunciados, às representações da marca - e seu próprio discurso é uma delas -, mas é um conceito significativo, produzido e compartilhado na atualidade identitária, no espaço simbólico social. Resumindo, a identidade é ideal, intangível, posicional, mediada por suas representações e somente estas é que podem ser objeto de proposições.

\section{Conceituando a marca: uma primeira síntese}

Diante das questões e discussões levantadas pela pesquisa, sugerimos que a marca contemporânea é um enunciador-indexador, um metadiscurso cujas estratégias enunciativas centralizam as gramáticas de produção e de reconhecimento de sentido para construir no espaço simbólico da atualidade identitária um lugar de ser, uma identidade e uma imagem. A natureza discursiva da marca é referencial e o seu caráter totalizante-convergente a torna, simultaneamente, depositária de ideologia e tributária de sentido, sendo causa e resultado de seu próprio discurso.

Julgamos prudente esclarecer que a síntese apresentada acima não é uma definição ou um conceito acabado da marca. Tomamos tal síntese por primeira, como o reflexo do momento atual de uma pesquisa que continua em andamento. Entendemos apenas por um ensaio das possibilidades de uma abordagem conceitual do fenômeno da marca, analisada na sua enunciação com base no campo da comunicação e pela perspectiva teórico-metodológica da produção de sentido.

\section{Concluindo... e agora?}

Avaliamos que esta pesquisa nos apontou um caminho plausível para a construção de uma teoria da marca, na medida em que conseguimos (1) identificar, por aquelas quatro características essenciais, que a sua natureza é discursiva; (2) avaliar, pela especificidade de mediação e intertextualidade da marca, que a possibilidade de sua teorização se daria pela abordagem de sua enunciação; e (3) pelo potencial explicativo e adequação dos pressupostos teórico-metodológicos da produção de sentido foi possível reconhecer, organizar, articular e analisar importantes elementos do fenômeno da marca contemporânea e de sua operacionalização. Percebemos que esta pesquisa, 
ao mesmo tempo em que ofereceu uma base para desenvolver ferramentas e análises voltadas para as aplicações das marcas, abriu perspectivas de prosseguir no caminho de uma teoria da marca.

Entendendo que a marca não é um fenômeno econômico, mas discursivo, o desenvolvimento de uma Teoria da Marca deve necessariamente passar pelo estudo de sua enunciação, o que significa, entre outras coisas, reconhecer sua intertextualidade e articulação discursiva entre as diversas esferas sociais. Isso nos permitiria apreender, descrever e explicar os vínculos e os processos formativos de um fenômeno que vem se impondo como a mais efetiva e centralizadora forma de modelação discursiva contemporânea, e compreender seu impacto sobre os processos sociais e as estratégias de gerenciamento das organizações. Não se trata de apenas descrever o que é o fenômeno, mas, sobretudo, de oferecer pontes e possibilidades de conexões teóricas que o expliquem nos diversos aspectos de sua multidimensionalidade e multiterritorialidade.

\section{Referências}

BERGER, Peter e LUCKMANN, Thomas. A construção social da realidade: tratado de sociologia do conhecimento. 24. ed. Petrópolis: Vozes, 2004.

COSTA, Joan. Imagen corporativa en el siglo XXI. 2. ed. Buenos Aires: La Crujía, 2006.

Imagen global. Enciclopedia Del Diseño. 2. ed. Barcelona: Ceac, 1989.

CHAVES, Norberto. La imagen corporativa: teoría y metodología de la identificación institucional. 2. ed. Barcelona: Gustavo Gili, 2003.

FAUSTO NETO, Antonio. Comunicação e mídia impressa: estudo sobre a AIDS. São Paulo: Hacker, 1999.

KAPFERER, Jean-Noël. As marcas, capital da empresa: criar e desenvolver marcas fortes. 3. ed. Porto Alegre: Bookman, 2003.

PEROTTO, Evandro Renato. Conceituando a marca pela enunciação: uma proposta do campo da comunicação. Brasília, 2007. 93 f.. Dissertação (Mestrado) - Faculdade de Comunicação, Programa de Pós-Graduação em Comunicação. Brasília: Universidade de Brasília, 2007.

SEMPRINI, Andrea. A marca pós-moderna: poder e fragilidade da marca na sociedade contemporânea. São Paulo: Estação das Letras, 2006.

VERÓN, Eliseo. Fragmentos de um tecido. São Leopoldo: Unisinos, 2005.

A produção de sentido. São Paulo: Cultrix, EdUSP, 1980.

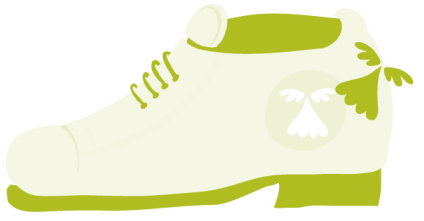

